\title{
Spontaneous and Evoked Activity of Substantia Nigra Pars Reticulata Neurons during High-Frequency Stimulation of the Subthalamic Nucleus
}

\author{
Nicolas Maurice, Anne-Marie Thierry, Jacques Glowinski, and Jean-Michel Deniau \\ Institut National de la Santé et de la Recherche Médicale U.114, Chaire de Neuropharmacologie, Collège de France, 75231 Paris Cedex 05, France
}

\begin{abstract}
The subthalamic nucleus (STN), a major component of the basal ganglia, exerts an excitatory influence on the output structures of this system i.e., the substantia nigra pars reticulata (SNR) and the internal segment of the globus pallidus. High-frequency stimulation of the STN is a method currently used to treat parkinsonian symptoms. The aim of the present study was to analyze the effects of STN high-frequency stimulation on the activity of SNR neurons and to investigate its impact on the transfer of information between the cerebral cortex and the SNR. During STN high-frequency stimulation, the activity of SNR cells was decreased at low-intensity stimulation, whereas it was increased at a higher intensity. The decrease in the discharge of SNR cells likely results from the activation of a GABAergic transmission in the SNR because this effect was blocked by local application of bicuculline. The increased activity likely results from the activation of the glutamatergic subthalamonigral projection because the latency of the evoked excitations was consistent with the conduction time of the subthalamonigral neurons. Finally, during STN high-frequency stimulation, the transmission of cortical information along the direct trans-striatal pathway was preserved, whereas the functionality of the trans-subthalamic pathways was partly preserved or completely blocked depending on the stimulation intensity. The present data indicate that STN high-frequency stimulation influences the activity of SNR cells through activation of their excitatory and inhibitory synaptic afferent pathways as well as antidromic activation of the projection neurons.
\end{abstract}

Key words: subthalamic nucleus; substantia nigra pars reticulata; basal ganglia; high-frequency stimulation; deep brain stimulation; Parkinson's disease; neuronal activity

\section{Introduction}

The subthalamic nucleus (STN) is a major component of the basal ganglia, which plays a critical role in the control of movement. The STN receives direct afferents from the frontal pole of the cerebral cortex including motor, premotor, and prefrontal areas (Monakow et al., 1978; Berendse and Groenewegen, 1991; Nambu et al., 1996) and indirect inputs from the entire cortical mantle through the striatum and the external segment of the globus pallidus (Smith et al., 1998). The STN participates in the transmission of cortical signals to the output nuclei of the basal ganglia i.e., the substantia nigra pars reticulata (SNR) and the internal segment of the globus pallidus (GPi) (Kitai and Deniau, 1981; Joel and Weiner, 1997; Smith et al., 1998). Via its glutamatergic projections, the STN provides a major excitatory drive onto the GABAergic neurons of SNR and GPi and thus reinforces the inhibitory influence of the basal ganglia on thalamic and brain-

Received July 11, 2003; revised Sept. 16, 2003; accepted Sept. 20, 2003.

This work was supported by Institut National de la Santé et de la Recherche Médicale, by Centre National de la Recherche Scientifique, and a grant from the Ministère de la Recherche et des Nouvelles Technologies (Action Concertée Incitative RMA02004JJA). We thank Annie Ménétrey for excellent histological assistance and Patrick L. Tierney for English correction.

Correspondence should be addressed to Dr. Nicolas Maurice, Institut National de la Santé et de la Recherche Médicale U.114, Chaire de Neuropharmacologie, Collège de France, 11 place Marcelin Berthelot, 75231 Paris Cedex 05, France. E-mail: nicolas.maurice@college-de-france.fr.

Copyright $\odot 2003$ Society for Neuroscience $\quad$ 0270-6474/03/239929-08\$15.00/0 stem premotor networks (Albin et al., 1989; Alexander and Crutcher, 1990; Chevalier and Deniau, 1990). Through this effect, the STN could participate in the scaling of movement and the selection of appropriate motor commands (Mink and Thach, 1993).

In the past 10 years, STN high-frequency stimulation has become an increasingly used method to treat the parkinsonian motor syndrome (Limousin et al., 1995). The effects of highfrequency stimulation of a deep brain structure are usually similar to those of a lesion (Benazzouz et al., 1995), suggesting that this type of stimulation acts by silencing neurons of the stimulated structure (Benabid et al., 2000; Dostrovsky and Lozano, 2002). In the case of Parkinson's disease, this hypothesis has led to focus on the STN as a major target for stimulation. Indeed, in parkinsonian patients (Levy et al., 2002) as well as in animal models of this disease (DeLong, 1990), STN neurons are hyperactive and discharge abnormal rhythmic bursts of spikes (Bevan et al., 2002). According to some in vitro data, STN high-frequency stimulation may silence STN neurons activity via a mechanism of depolarization block (Beurrier et al., 2001; Magarinos-Ascone et al., 2002). However, in vivo observations have suggested that this type of stimulation may produce its beneficial influence by activating axons of STN cells, STN afferents, or fibers passing close to the stimulation site (Dostrovsky and Lozano, 2002; Salin et al., 2002; Vitek, 2002). To further clarify the mechanisms involved, 
we have analyzed the effects of STN high-frequency stimulation on the spontaneous activity of SNR neurons and determined to which extent the transfer of information between the cerebral cortex and the SNR is modified by STN stimulation. Extracellular single-unit recordings of SNR cells were thus performed in anesthetized rats during STN high-frequency stimulation, and responses were compared to those evoked by single pulse stimulation to reveal a possible high-frequency stimulation-specific influence. In addition, responses induced in SNR cells by electrical stimulation of the motor cortex were investigated before and during STN stimulation.

\section{Materials and Methods}

Experiments were performed in 20 adult male Sprague Dawley rats weighing 300-330 gm (IFFA CREDO, Les Oncins, France). Animals were anesthetized with chloral hydrate $(400 \mathrm{mg} / \mathrm{kg}$, i.p.; supplemented by continuous intraperitoneal injection of chloral hydrate delivered at a rate of $60 \mathrm{mg} \cdot \mathrm{kg}^{-1} \cdot \mathrm{hr}^{-1}$ using a peristaltic pump) and fixed in a conventional stereotaxic head frame (Horsley Clarke Apparatus, Unimécanique, Epinay-sur-Seine, France). Body temperature was monitored by a rectal thermometer and maintained at $36.5^{\circ} \mathrm{C}$ with a homeothermic blanket (Harvard Apparatus, Kent, UK). All experiments were conducted in accordance with the Policies on the Use of Animals in Neuroscience as approved by the Society for Neuroscience.

Electrophysiological analysis. Single-unit activity of SNR cells was recorded extracellularly using glass micropipettes $(6-8 \mathrm{M} \Omega)$ filled with a 0.6 m sodium chloride solution containing 4\% Pontamine Sky Blue. Single neuron action potentials were amplified with a differential preamplifier (ISO-80; World Precision Instruments, Hertfordshire, UK) and displayed on a memory oscilloscope (Tektronix, Courtaboeuf, France). Nigral neurons were identified as nondopaminergic by their classically defined electrophysiological characteristics: thin spikes (width $<2 \mathrm{msec}$ ) and ability to present relatively high-frequency discharges $(>10 \mathrm{~Hz})$ without decrease in spike amplitude (Bunney et al., 1973; Deniau et al., 1978a; Guyenet and Aghajanian, 1978). During the application of STN stimulation at $1 \mathrm{~Hz}$, spikes and stimulation artifacts were separated from noise using the single-threshold function of a window discriminator (121 window discriminator; World Precision Instruments) and sampled online on a computer connected to a CED 1401 interface using the spike 2 data acquisition program (Cambridge Electronic Design, Cambridge, UK). Peristimulus time histograms were generated from 50 stimulation trials. During the application of STN high-frequency stimulation, spikes were discriminated from noise and from stimulation artifacts on the basis of their amplitude using the gate function (double threshold) of the discriminator. Accordingly, signals corresponding to spikes were only sampled. In a second step, all recordings were checked off-line, at a high scale (30 msec per computer screen) to verify that all spikes were correctly sampled and that stimulation artifacts were not taken. The time during which spikes recording is occulted by saturation of amplifier after stimulation $(0.3 \mathrm{msec})$ has been taken into account to calculate the firing rates during stimulation.

Stimulation procedures. Electrical stimulation of the orofacial motor cortex [anterior (a): $12.5 \mathrm{~mm}$ from the interaural line; lateral (1): $3.8 \mathrm{~mm}$; depth: $1.2 \mathrm{~mm}$ from the cortical surface) and of the STN (a: $5.2 \mathrm{~mm}$ from the interaural line; $1: 2.5 \mathrm{~mm}$ ) ipsilateral to the recording site in the SNR, was performed with bipolar coaxial stainless steel electrodes (diameter, $250 \mu \mathrm{m}$; tip-barrel distance, $300 \mu \mathrm{m}$; SNE-100, Rhodes Medical Instruments, Woodlands Hill, CA) positioned stereotaxically according to the atlas of Paxinos and Watson (1986). The recording site in the SNR (a: $3.0-3.4 \mathrm{~mm}$ from the interaural line; $1: 2.3-2.6 \mathrm{~mm}$ ) was localized in the lateral sensorimotor division of the nucleus (Deniau et al., 1996), which receives the projections of the stimulated region in the STN (Kolomiets et al., 2003). The positioning of the stimulating electrode within the orofacial motor cortex was precisely defined by the motor response evoked by a brief train of pulses (pulses of $100 \mu$ sec width and $10-20 \mathrm{~V}$ delivered at a $250 \mathrm{~Hz}$ frequency during $300 \mathrm{msec}$ ). To ensure correct positioning of the stimulating electrode into the STN, multiunit responses to cortical stimulation were recorded through the stimulating electrode. As previ- ously described, cortical stimulation evokes characteristic responses in STN cells consisting of two excitatory responses separated by a brief inhibition (Ryan and Clark, 1992; Maurice et al., 1998). When applied in the cortex, electrical stimulation consisted of pulses of $200 \mu \mathrm{sec}$ width and $10-20 \mathrm{~V}$ (corresponding to $200-400 \mu \mathrm{A}$ ) delivered at a $1 \mathrm{~Hz}$ frequency. Electrical STN stimulation consisted of pulses of $60 \mu \mathrm{sec}$ width and $1-15 \mathrm{~V}$ (corresponding to $20-300 \mu \mathrm{A}$ intensity) delivered at a $1 \mathrm{~Hz}$ frequency for the single-pulse study and $50-200 \mathrm{~Hz}$ for the highfrequency study.

Microiontophoresis. Three-barrel glass micropipettes (3GC120F-10; Clark Electromedical Instruments, Reading, UK) were pulled on a vertical pipette puller (Narishige, Tokyo, Japan), and their tips were broken under microscopic observation to a diameter of $1-3 \mu \mathrm{m}$. Two barrels were filled with a solution of $(-)$ bicuculline methiodide $(5 \mathrm{~mm}$ in $\mathrm{NaCl}$ $9 \%$, $\mathrm{pH} 3$; Sigma; St. Louis, MO) and one barrel with a solution of GABA (1 $\mathrm{M}$ in $\mathrm{H}_{2} \mathrm{O}$, pH 4; Sigma). Barrels impedance was 40-70 $\mathrm{M} \Omega$. The three-barrel microelectrode was then glued to the recording electrode under microscopic control to a tip-tip distance of $10 \mu \mathrm{m}$, this particular position reducing currents artifacts (Crossman et al., 1974). Iontophoretic currents were delivered using an iontophoresis unit (Bionic Instruments, Briis sous Forges, France). A retaining current ( -5 to -20 $\mathrm{nA}$ ) was applied to each barrel to prevent passive diffusion between ejection periods. All compounds were ejected by a positive current adjusted to provide submaximal responses.

Statistical analysis. Results are given as means \pm SEM. Differences in SNR firing rate observed before and during STN high-frequency stimulation were evaluated using the two-tailed Student's $t$ test. Responses to STN stimulation at different frequencies were compared by a one-way ANOVA followed by a Dunnett's multiple comparison test.

Histological verifications. At the end of each experiment, the tip of each stimulating electrode was marked by an electrical deposit of iron $(15 \mu \mathrm{A}$ anodal, $20 \mathrm{sec}$ ) and observed on histological sections after a ferriferrocyanide reaction. The tip of the recording electrode was marked by iontophoretic ejection of Pontamine Sky Blue ( $8 \mu \mathrm{A}$ cathodal, $20 \mathrm{~min}$ ), allowing the determination of the position of recorded cells. Brains were removed and fixed in a $10 \%$ formalin solution. The localization of the blue points was observed on serial frozen sections $(100 \mu \mathrm{m})$ stained with safranin.

\section{Results}

\section{Effects of STN high-frequency stimulation on the activity of SNR neurons}

The effects of STN high-frequency stimulation $(130 \mathrm{~Hz})$ on the activity of ipsilateral SNR neurons were examined in 129 cells. For each tested cell, STN high-frequency stimulation was applied for at least $30 \mathrm{sec}$. Three types of effects were observed: inhibition, excitation, and/or antidromic activation. These responses could be obtained on a same SNR cell depending on the intensity and polarity of the stimulation pulses and were distributed throughout the recording area in the SNR.

\section{Inhibition}

During STN high-frequency stimulation at low intensity $(1-4 \mathrm{~V}$ corresponding to $20-80 \mu \mathrm{A})$, SNR cells $(n=84)$ showed a marked decrease (79\%; range: $25-100 \%)$ in discharge rate. The mean firing rate of these cells was $27.3 \pm 2.0 \mathrm{~Hz}$ before stimulation and decreased to $5.9 \pm 1.1 \mathrm{~Hz}(p<0.001)$ during STN stimulation. As illustrated in Figure 1, $A$ and $B$, the firing of these SNR cells dropped abruptly at the onset of the stimulation, and this reduced firing was maintained throughout the stimulation period while cells rapidly recovered $(40-900 \mathrm{msec})$ the prestimulus firing rate after cessation of the stimulation. In a few neurons, the inhibition outlasted (up to $5 \mathrm{sec}$ ) the period of STN stimulation with a gradual recovery of the firing rate. This postinhibitory effect was generally prolonged by increasing the stimulation intensity.

The influence of the frequency of STN stimulation was exam- 


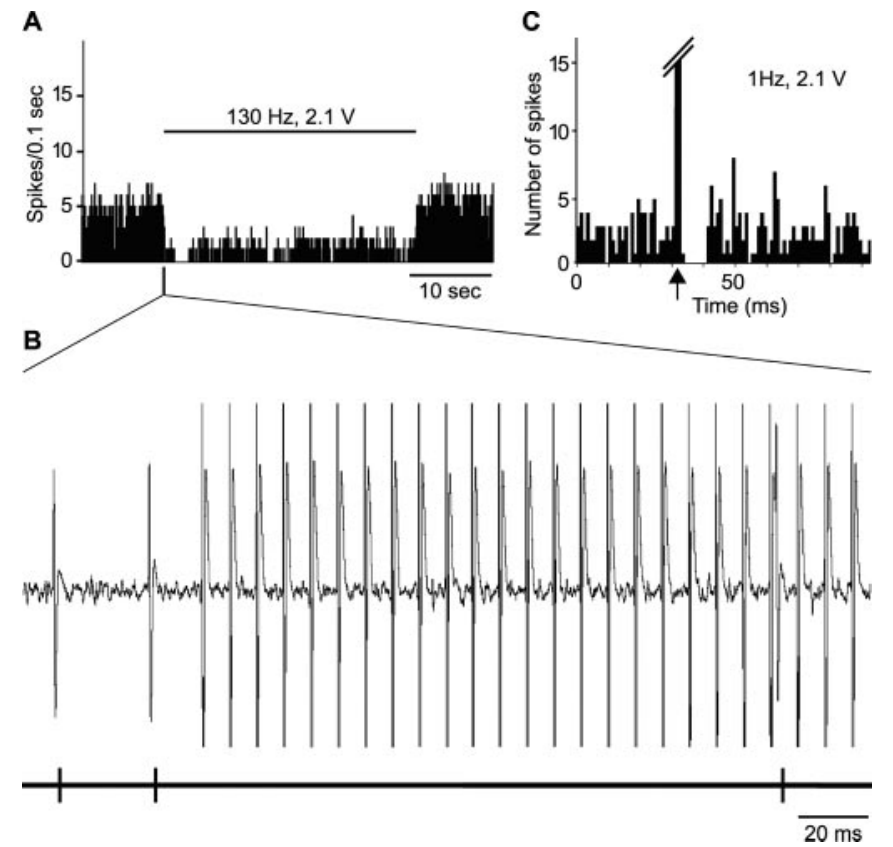

Figure 1. Inhibitory effect of STN high-frequency stimulation on the spontaneous activity of a SNR cell. $A$, Rate histogram illustrating the decreased spontaneous firing of a SNR cell during STN high-frequency stimulation (130 Hz) applied at low intensity (2.1 V); horizontal line indicates the time of application of STN stimulation. B, Magnified view of the recording (top trace) depicting the onset of STN high-frequency stimulation and of the event channel (bottom trace) confirming that only spikes were sampled. C, Peristimulus time histogram illustrating the inhibitory response evoked in the same SNR cell by STN stimulation at the same intensity but at 1 $\mathrm{Hz}$. Arrow indicates the time of the stimulation application.

ined in 15 of the 84 neurons whose firing was decreased by lowintensity $(<4 \mathrm{~V})$ STN stimulation at $130 \mathrm{~Hz}$. The mean spontaneous firing rate of these cells $(23.6 \pm 2.5 \mathrm{~Hz})$ decreased to $10.9 \pm$ 2.3 and $5.2 \pm 1.5 \mathrm{~Hz}$ during STN stimulation at 50 and $100 \mathrm{~Hz}$, respectively. Increasing the stimulation frequency to 130 and 200 $\mathrm{Hz}$ did not further significantly reduce the firing of SNR cells $(4.1 \pm 1.1$ and $4.1 \pm 1.2 \mathrm{~Hz}$, respectively; $p>0.05)$.

\section{Excitation}

During STN high-frequency stimulation $(130 \mathrm{~Hz})$, the discharge of SNR cells was increased in 28 of the 129 cells tested (Fig. 2). Usually this excitatory response was evoked using a stimulation intensity above $4 \mathrm{~V}$ and could be obtained in cells presenting an inhibition at low intensity $(n=13)$ (Fig. 3). The mean firing of the cells increased up to $84.6 \pm 9.6 \mathrm{~Hz}$ during STN stimulation as compared with $25.0 \pm 3.9 \mathrm{~Hz}$ before stimulation $(p<0.001)$. In most of the SNR cells activated by STN high-frequency stimulation, the firing increased promptly at the onset of the stimulation, and the excitation was maintained throughout the stimulation period and rapidly returned to the prestimulus rate when the stimulation was ended. However, in the cells presenting an inhibition at low stimulation intensity, the increased discharge evoked by STN stimulation at higher intensity could be preceded by a transient period of decreased activity.

The influence of the frequency of STN stimulation was examined in 5 of the 28 SNR cells activated by STN stimulation at 130 $\mathrm{Hz}$. The mean firing rate of these cells $(35.0 \pm 7.2 \mathrm{~Hz}$ before stimulation) increased to $51.1 \pm 8.2,88.0 \pm 10.7$, and $109.1 \pm$ $14.1 \mathrm{~Hz}$ during STN stimulation at 50, 100, and $130 \mathrm{~Hz}$, respectively.
A

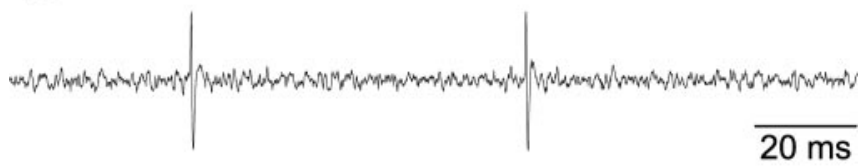

B
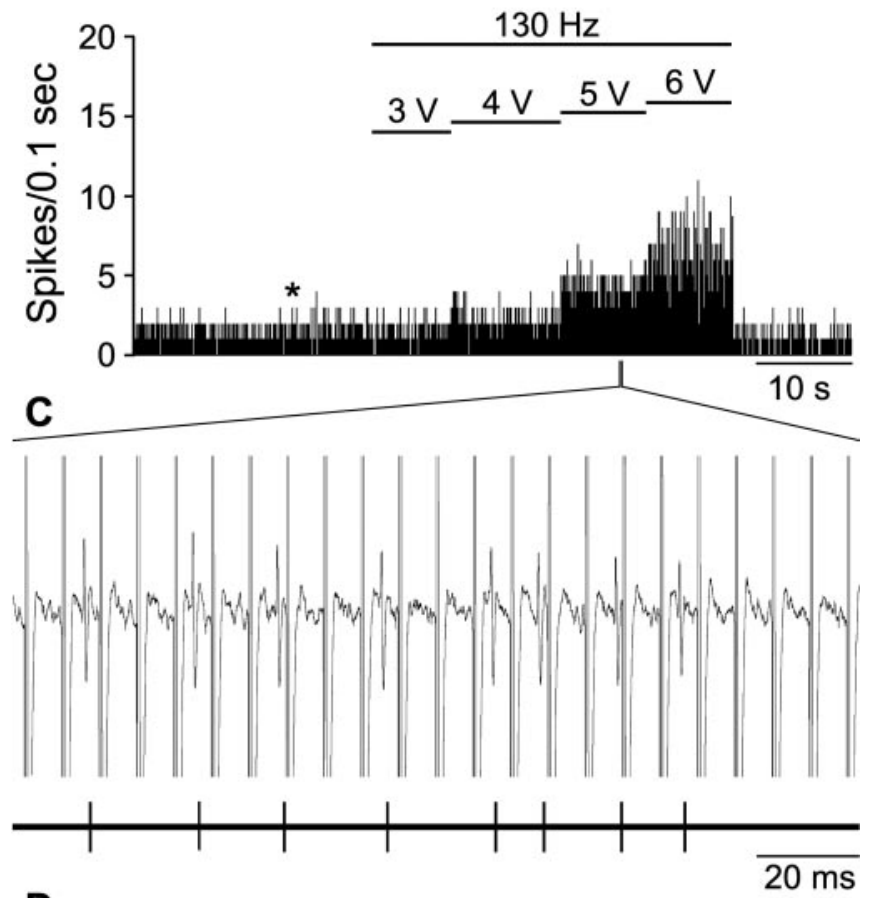

D

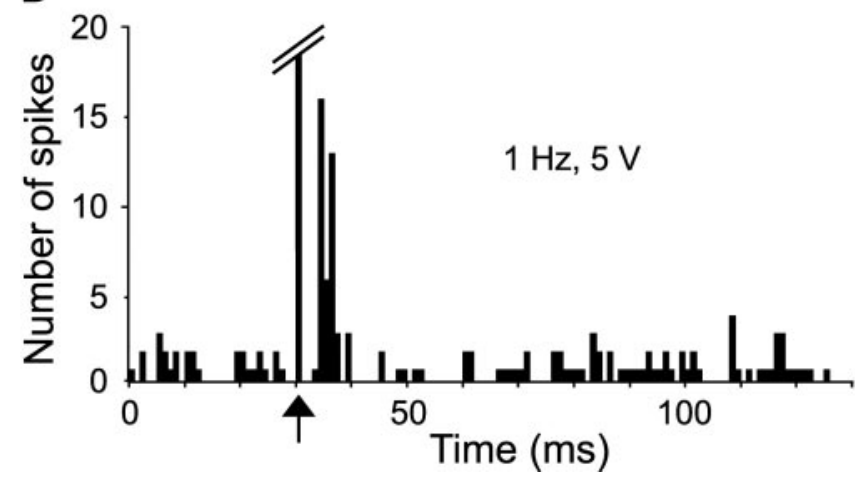

Figure 2. Excitatory effect of STN high-frequency stimulation on the activity of a SNR cell. A, Activity trace recorded before STN high-frequency stimulation taken at the time indicated by the star in $B . B$, Rate histogram illustrating the evoked increase of firing of a SNR cell during STN high-frequency stimulation ( $130 \mathrm{~Hz}$ ) with increasing intensities $(3,4,5$, and $6 \mathrm{~V})$; horizontal lines indicate the time of application of STN stimulation with the corresponding intensity; note that the excitatory effect is elicited only during the application of STN stimulation at high intensity. C, Magnified view of the recording (top trace) and of the event channel (bottom trace), confirming that only spikes were sampled. D, Peristimulus time histogram illustrating the excitatory response evoked in the same SNR cell by STN stimulation at $1 \mathrm{~Hz}$ and 5 V. Arrow indicates the time of the stimulation application.

\section{Antidromic activation}

STN stimulation induced an antidromic activation in 20 SNR cells, with a mean latency of $1.2 \pm 0.1 \mathrm{msec}$ (Fig. 4). The antidromic responses were obtained for stimulation intensities of $2-8 \mathrm{~V}$. In all cases, the antidromic spike reliably followed the 130 $\mathrm{Hz}$ stimulation (Fig. 4B) and could be maintained up to $600 \mathrm{~Hz}$. Interestingly, the occurrence of an antidromic spike elicited by 

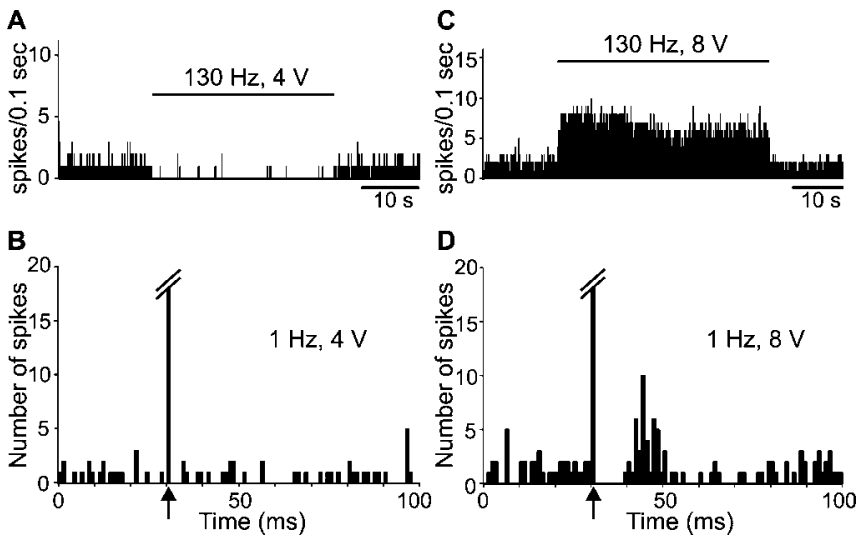

Figure 3. Inhibitory and excitatory effects evoked by STN stimulation on a same SNR cell. $A$, Inhibition of spontaneous activity induced on a SNR cell by STN high-frequency stimulation (130 $\mathrm{Hz}$ ) at low intensity (4 V). B, STN stimulation by single pulses at $1 \mathrm{~Hz}$ and at the same intensity (4 V) did not evoke any response in this SNR cell. C, Excitatory effect evoked on the same SNR cell by STN high-frequency stimulation $(130 \mathrm{~Hz})$ at a higher intensity $(8 \mathrm{~V})$. D, STN stimulation by single pulses at $1 \mathrm{~Hz}$ and at the same intensity $(8 \mathrm{~V})$ evoked an excitatory response preceded by an inhibition. In $A$ and $C$, horizontal lines indicate the time of application of STN stimulation at high frequency; in $B$ and $D$, arrows indicate the time of application of the single pulse stimulation.
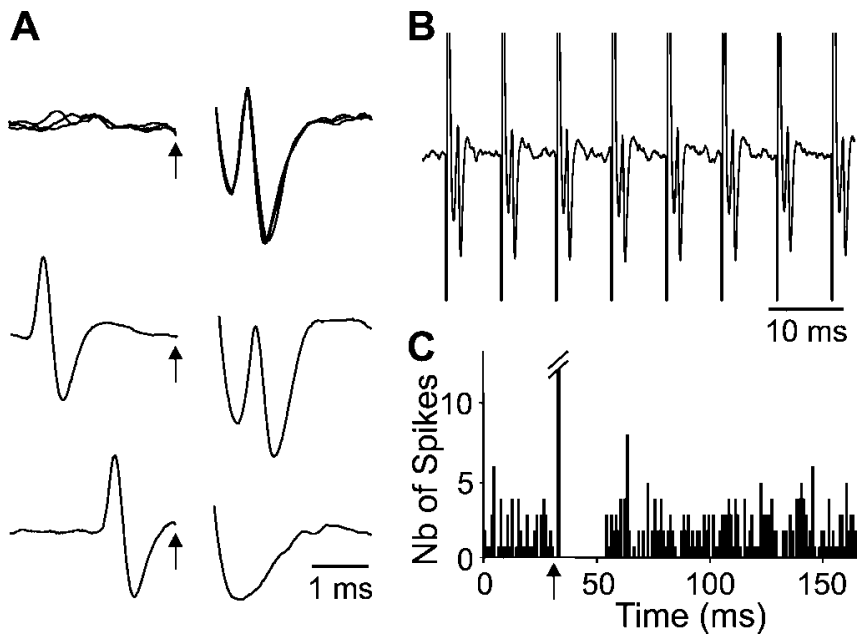

Figure 4. Antidromic activation of a SNR cell during STN high-frequency stimulation. $A$, Characterization of the antidromic response evoked by STN stimulation. Fixed latency (top; three superimposed traces; antidromic latency: $0.9 \mathrm{msec}$ ) and collision with spontaneous spikes (middle and bottom). B, The antidromic spike reliably follows $130 \mathrm{~Hz}$ stimulation. C, Peristimulus time histogram illustrating that in this SNR cell, the antidromic activation evoked by STN stimulation at $1 \mathrm{~Hz}$ and $2.5 \mathrm{~V}$ was followed by a period of inhibition. Arrows indicate the time of stimulation.

STN stimulation at $1 \mathrm{~Hz}$ was systematically followed by a silent period lasting 8-21 msec (Fig. 4C). Consequently, during STN stimulation at $130 \mathrm{~Hz}$, the spontaneous firing of the neuron was suppressed.

High-frequency $(130 \mathrm{~Hz})$ versus single-pulse $(1 \mathrm{~Hz})$ stimulation of the STN

In 57 SNR cells, responses induced by STN high-frequency stimulation at $130 \mathrm{~Hz}$ were compared with those evoked by a singlepulse stimulation $(1 \mathrm{~Hz})$ applied with similar intensity and duration $(60 \mu \mathrm{sec})$. Single-pulse stimulation induced a brief inhibitory response [latency $(\mathrm{L})=4.4 \pm 1.4 \mathrm{msec}$; duration (D) $=13.6 \pm 1.3 \mathrm{msec}$ ] in 33 of the 39 cells whose firing was decreased during high-frequency stimulation (Fig. 1C), no effect
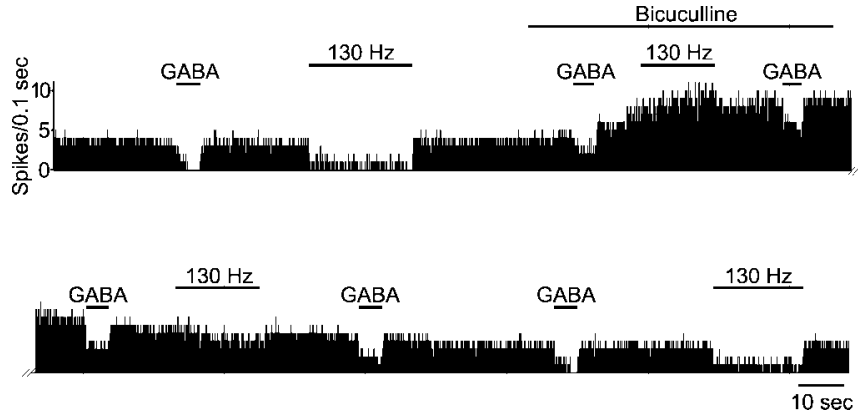

Figure 5. Iontophoretic application of bicuculline blocks the inhibitory effect induced by STN high-frequency stimulation at low intensity on the activity of a SNR cell. The efficiency of bicuculline to block the GABAergic transmission is ascertained by its ability to reverse the effect of iontophoretic application of GABA. Although the GABA response is blocked, STN high-frequency stimulation $(130 \mathrm{~Hz} ; 5 \mathrm{~V})$ is no longer able to decrease the spontaneous activity of the SNR cell. After cessation of bicuculline application, the inhibitory effect of STN stimulation concomitantly recovered with the sensitivity of the cell to GABA. Horizontal lines indicate the time of GABA and/or bicuculline iontophoretic application and the time of STN high-frequency stimulation application, as indicated by the corresponding headlines.

being observed in the six remaining cells. An excitatory response $(\mathrm{L}=5.0 \pm 0.8 \mathrm{msec})$ was also evoked by the single-pulse stimulation in 13 of the 14 SNR cells activated by STN high-frequency stimulation (Fig. 2C), and no effect was observed in the remaining cell. The latencies of excitatory responses evoked by single pulses and by high-frequency stimulation were similar. The excitatory responses were preceded by a brief inhibition in 4 of the 13 cells activated by the single-pulse stimulation. Finally, the neurons antidromically activated during high-frequency stimulation $(n=9)$ were also antidromically activated at a same latency using single pulse stimulation. Activation threshold was the same or slightly higher with single pulse stimulation.

Involvement of a GABAergic transmission in the inhibition induced by STN high-frequency stimulation

To test the hypothesis that the decreased firing rate observed in SNR cells during STN high-frequency stimulation results from the activation of a GABAergic transmission, $\mathrm{GABA}_{\mathrm{A}}$ receptors were blocked by iontophoretic application of bicuculline on SNR cells (Fig. 5). In all SNR tested cells $(n=13)$, a bicuculline application at a current that antagonized the effect of GABA $(74.9 \%$ reduction in efficacy) also blocked the inhibition induced by STN stimulation $(130 \mathrm{~Hz})$. After cessation of bicuculline application, the inhibitory effect of STN high-frequency stimulation recovered concomitantly with the sensitivity of the cells to GABA.

Effects of STN high-frequency stimulation on responses evoked in SNR cells by stimulation of the motor cortex Responses evoked in SNR cells by single-pulse stimulations (1 $\mathrm{Hz}$ ) of the motor cortex before and during STN high-frequency stimulation $(130 \mathrm{~Hz})$ were compared to determine the impact of STN high-frequency stimulation on the transmission of cortical information through the trans-striatal and trans-subthalamic circuits (Figs. 6, 7). As previously described (Maurice et al., 1999; Kolomiets et al., 2003), the cortical stimulation induced different patterns of responses consisting of an inhibition $(\mathrm{L}=12.3 \pm 0.6$ msec; $\mathrm{D}=20.5 \pm 2.1 \mathrm{msec}$ ) preceded or not by an early excitation $(\mathrm{L}=4.4 \pm 0.1 \mathrm{msec})$ and followed or not by a late excitation $(\mathrm{L}=31.7 \pm 0.5 \mathrm{msec})$. The early excitation results from the activation of the direct subthalamonigral pathway, the inhibition from the activation of the direct striatonigral pathway, and the late excitatory response from the activation of the so-called indi- 

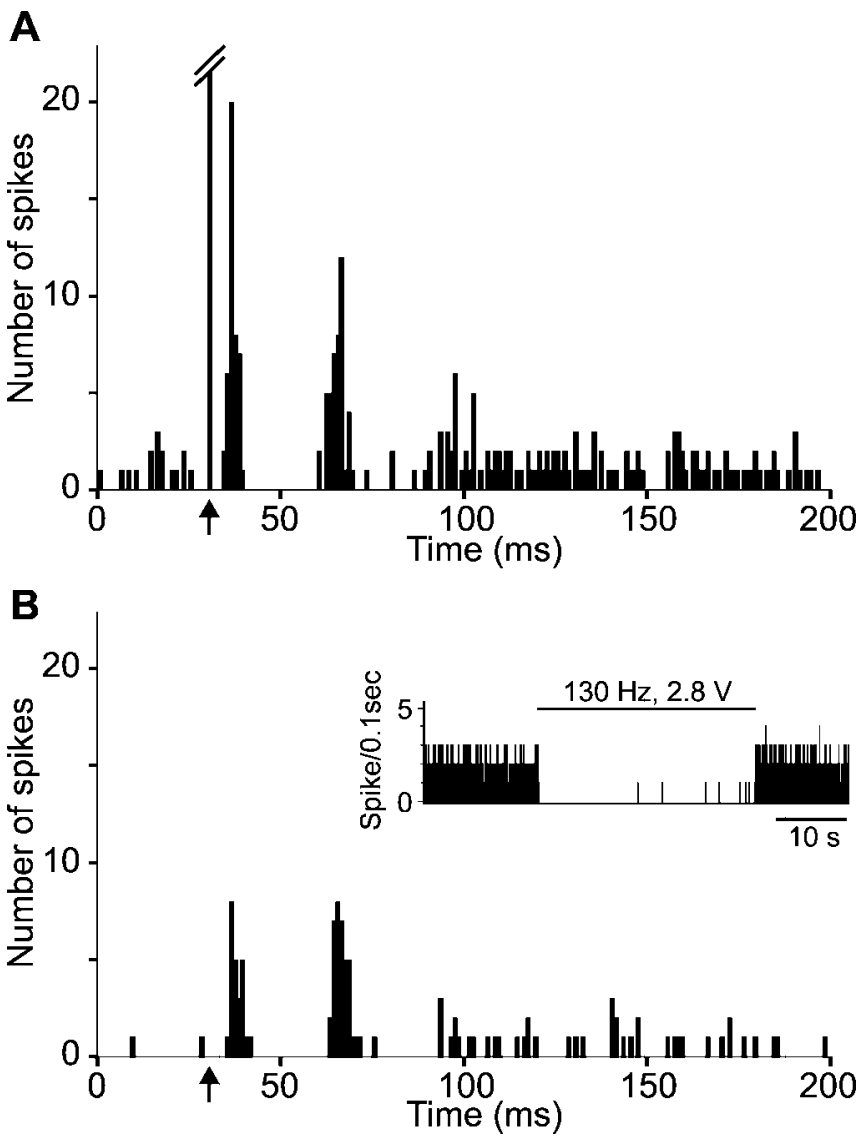

Figure 6. Impact of STN high-frequency stimulation at low intensity on the pattern of responses evoked by cortical stimulation in a SNR cell. $A$, Triphasic excitatory-inhibitory- excitatory pattern of response evoked by stimulation of the orofacial sensorimotor cortex while the STN stimulation is turned off. $B$, During the STN high-frequency stimulation $(130 \mathrm{~Hz})$ at low intensity $(2.8 \mathrm{~V})$ that produced a marked inhibition of the cell activity, responses evoked by cortical stimulation presented a similar pattern, although excitations were decreased; inset, inhibitory effect of STN high-frequency stimulation on the spontaneous activity of the recorded SNR cell. Arrows indicate the time of stimulation.

rect striato-pallido-subthalamonigral pathway, which induces a disinhibition of the STN (Kitai and Deniau, 1981; Maurice et al., 1999; Nambu et al., 2000).

Cortically evoked responses were studied in 13 SNR cells inhibited (mean decreased firing rate 90\%) and 8 SNR neurons activated (mean increased firing $184 \%$ ) by STN stimulation. In the 13 inhibited cells, when the STN high-frequency stimulation was applied just above the intensity threshold to induce an inhibitory effect $(1-4 \mathrm{~V})$, the patterns of responses evoked by the cerebral cortex were preserved, although the early and late excitatory responses were decreased by 56 and 35\%, respectively (Fig. $6)$. In contrast, excitatory responses were no more observed when the stimulation intensity was raised to a suprathreshold level $(n=$ 3 ). In the eight SNR cells activated by the STN stimulation (intensity range: $4.5-13.5 \mathrm{~V}$ ), the components of the cortically evoked responses were differently affected: the late excitatory response was consistently abolished, the early excitatory response was either decreased or abolished, and the inhibition was maintained or even increased in duration (Fig. 7).

\section{Discussion}

The present study indicates that STN high-frequency stimulation influences SNR neuronal firing by activating inhibitory and excitatory pathways. Low-intensity stimulation induced an inhibi-
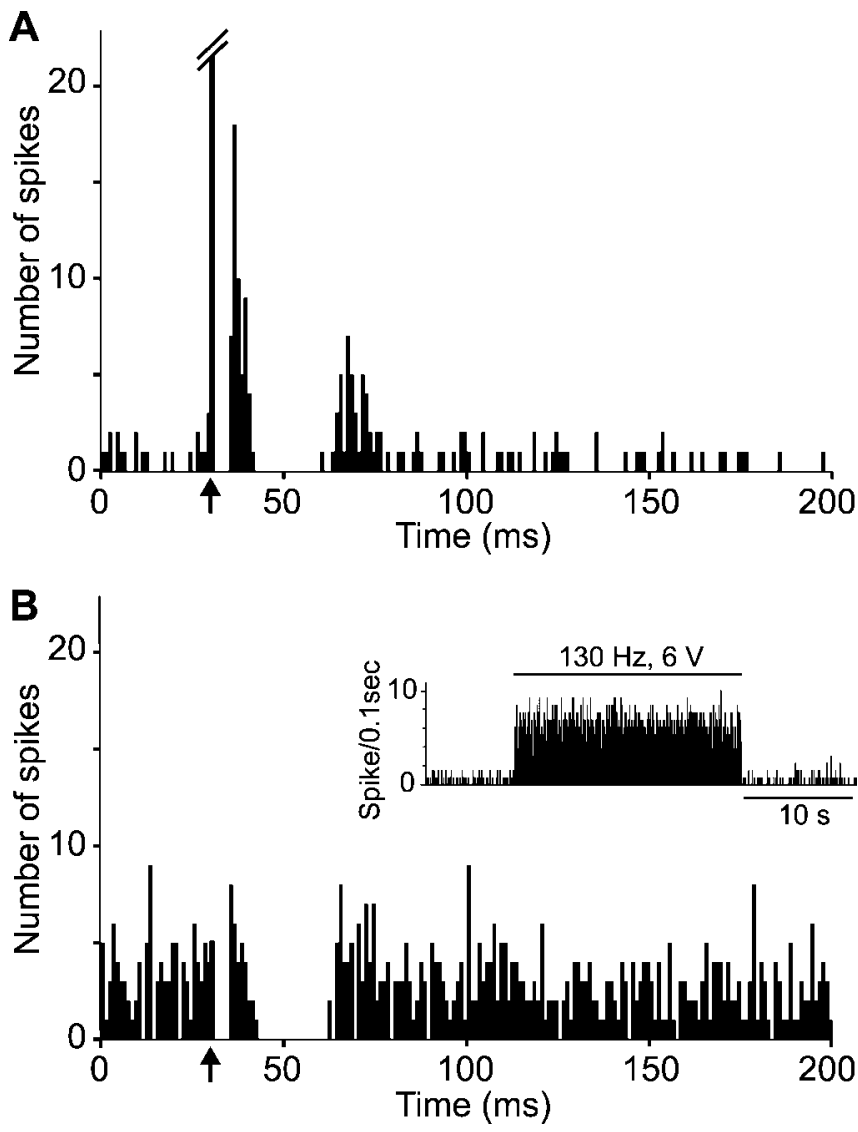

Figure 7. Impact of STN high-frequency stimulation at high intensity on the pattern of responses evoked by cortical stimulation in a SNR cell. $A$, Classical triphasic excitatoryinhibitory- excitatory events evoked by stimulation of the orofacial sensorimotor cortex on the SNR cell while the STN stimulation is turned off. B, During STN high-frequency stimulation (130 $\mathrm{Hz}$ ) at high intensity (6 V) that triggered an increase in the spontaneous firing rate of the cell, excitations were not observed anymore, whereas the inhibitory period was preserved; inset, excitatory effect of STN high-frequency stimulation on the spontaneous activity of the recorded SNR cell. Arrows indicate the time of stimulation.

tion by increasing GABAergic transmission in the SNR. In contrast, higher intensity stimulation elicited an excitation likely resulting from the activation of the subthalamonigral pathway. In both cases, the functionality of the direct inhibitory trans-striatal pathway was preserved, whereas the transmission of cortical information along the trans-subthalamic pathway was markedly decreased or blocked by increasing STN stimulation intensity.

Effects of STN high-frequency stimulation on the activity of SNR cells

Mechanisms underlying the effects of STN high-frequency stimulation on the output nuclei of the basal ganglia are still controversial. In parkinsonian patients and animal models of Parkinson's disease, lesion (Bergman et al., 1990; Aziz et al., 1991) or pharmacological inactivation (Levy et al., 2001) as well as STN high-frequency stimulation (Benazzouz et al., 1993; Limousin et al., 1995) produce similar beneficial effects on motor symptoms. These observations have led to propose that STN high-frequency stimulation acts by inhibiting STN neuronal activity and consequently by decreasing the excitatory drive of STN on basal ganglia output nuclei. Supporting this hypothesis, it has been shown that in rat brain slices STN high-frequency stimulation interrupts the firing of STN cells by reducing $\mathrm{Na}^{+}$and $\mathrm{Ca}^{2+}$ voltage-gated currents (Beurrier et al., 2001; Magarinos-Ascone et al., 2002). Fur- 
thermore, in anesthetized rats, a decrease of neuronal activity has been observed in the STN as well as in output nuclei of the basal ganglia after (Benazzouz et al., 1995, 2000) or during (Burbaud et al., 1994) application of STN high-frequency stimulation. However, as recently shown in monkeys, STN high-frequency stimulation can also increase the activity of basal ganglia output nuclei (Hashimoto et al., 2003). Finally, intracerebral microdialysis studies in rats indicate that extracellular levels of both glutamate and GABA are enhanced in the substantia nigra during STN highfrequency stimulation (Windels et al., 2000, 2003), suggesting the involvement of excitatory and inhibitory elements of the basal ganglia circuitry.

The present electrophysiological study indicates that lowintensity STN stimulation $(<4 \mathrm{~V})$ at either $1 \mathrm{~Hz}$ or high frequency $(130 \mathrm{~Hz})$ mainly induced an inhibition in SNR cells, whereas higher intensity stimulation (5-12 V corresponding to $100-240 \mu \mathrm{A})$ induced an excitation. The excitation likely results from the activation of the subthalamonigral pathway, which is glutamatergic (Hammond et al., 1978). Indeed, latencies of excitatory responses evoked in nigral cells by single pulse or highfrequency STN stimulation were similar and consistent with the conduction time of the subthalamonigral pathway (Deniau et al., 1978b; Kitai and Deniau, 1981). In addition, it has been shown that excitatory responses evoked in SNR by STN stimulation with current intensity $<300 \mu \mathrm{A}$ result from specific activation of the subthalamonigral fibers (Hammond et al., 1978). The inhibition evoked by low-intensity STN stimulation results from the activation of a GABAergic transmission in the SNR because this inhibition was suppressed by iontophoretic application on SNR cells of bicuculline, an antagonist of $\mathrm{GABA}_{\mathrm{A}}$ receptors. This inhibitory effect, which is observed at low-intensity STN stimulation, likely did not result from the activation of the direct GABAergic striatonigral fibers that run in the vicinity of the STN (Hammond et al., 1978). Indeed, if these fibers were activated, a continuous barrage of antidromic spikes would be generated along the striatonigral fibers preventing orthodromic volleys from reaching the SNR. However, as shown by our results, the inhibitory component of the response evoked in SNR cells by cortical stimulation, which is attributable to the activation of the striatonigral pathway, was preserved during STN high-frequency stimulation. The inhibition of nigral cells induced by single-pulse or highfrequency STN stimulation at low intensity could result from the activation of pallidonigral fibers through an axonal reflex because GABAergic pallido-subthalamic neurons send an axon collateral to the SNR (Kita and Kitai, 1994). Finally, this nigral inhibition could also result, through an axonal reflex, from the activation of the intranigral axon collateral network of GABAergic SNR cells (Deniau et al., 1982; Mailly et al., 2003) because ascending projections of nigral cells pass through the STN (Grofova et al., 1982). Several observations favor this latter hypothesis: (1) lowintensity STN stimulation generates antidromic activation of SNR cells (present study); (2) antidromic activation of nigral cells induces, through a local axonal reflex, IPSPs in SNR cells that follow frequency stimulations at $150-200 \mathrm{~Hz}$ (Deniau et al., 1982), and finally (3) the short duration of these IPSPs is consistent with the phasic inhibitory response observed in nigral cells after STN stimulation at $1 \mathrm{~Hz}$ (present study). Thus, the inhibition of nigral cells by STN high-frequency stimulation likely results from the temporal summation of these IPSPs.

As indicated by comparing the latencies of the antidromic spikes evoked in STN cells after SNR stimulation (Deniau et al., 1978b; Kitai and Deniau, 1981) with those evoked in SNR cells after STN stimulation (present study), the axons of SNR cells passing through the STN have a faster conduction velocity than the axons of the subthalamonigral neurons, suggesting that they are thicker. Large axons are more easily activated by electrical current than thinner ones (Ranck, 1975). Thus, it is likely that at low intensity STN stimulation preferentially activates the ascending axons of SNR cells, whereas a higher intensity is necessary to recruit subthalamonigral fibers. Accordingly, excitation of nigral cells was observed for higher intensity STN stimulation than that required for inhibition and antidromic activation.

\section{Effects of STN high-frequency stimulation on the transfer of cortical information}

As previously described, cortical stimulation induced complex responses in SNR cells that are composed of either a prolonged excitation or of an inhibition preceded or not by an early excitation and followed or not by a late excitation (Fujimoto and Kita, 1992; Kita, 1994; Ryan and Sanders, 1994; Maurice et al., 1999; Kolomiets et al., 2003). The inhibition is caused by the activation of the direct striatonigral pathway, whereas the early and late excitations result from the activation of the two transsubthalamic circuits (Maurice et al., 1998, 1999). The present study shows that the pattern of the responses evoked in SNR cells by stimulation of the orofacial motor cortex was preserved during STN high-frequency stimulation at low intensity. Indeed, the striatonigral inhibitory component was not modified, and the trans-subthalamic excitatory responses were still observed, although they were reduced. The reduction of these excitatory responses likely results from an activation of a nigral GABAergic transmission, as discussed above. During STN stimulation at higher intensity, the inhibitory component was preserved, but the excitatory components were not anymore observed, also suggesting a blockade of trans-subthalamic circuits at the level of the STN. This can be caused by a decreased excitability of STN cells resulting from the activation of the GABAergic pallidosubthalamic afferents and/or from a depolarization block of the STN cells. An additional mechanism might consist in the blockade of the synaptically mediated activation of STN cells from propagating to SNR caused by the collision with a barrage of antidromic spikes generated along the STN axons by the highfrequency stimulation.

\section{Functional considerations}

In current models of basal ganglia circuitry, the activation of the direct striatonigral GABAergic pathway inhibits the tonically active GABAergic projection neurons of the SNR and leads to a disinhibition of their target nuclei in thalamic and brainstem premotor networks (Chevalier and Deniau, 1990). This disinhibitory process is central in the physiology of the basal ganglia. Through their excitatory influence on SNR, the transsubthalamic pathways participate in the spatiotemporal shaping of this disinhibitory process and thus contribute to the scaling of movements and inhibition of competing motor programs (Mink and Thach, 1993). In parkinsonian patients and experimental models of Parkinson's disease, the firing pattern of STN cells is modified, and their overall firing rate is increased (DeLong, 1990; Bevan et al., 2002; Levy et al., 2002). These modifications in STN firing lead to an abnormal activity of the output nuclei of the basal ganglia and to an imbalance between the direct striatonigral and the trans-subthalamic pathways that is responsible for the motor disturbances (Albin et al., 1989; Chesselet and Delfs, 1996; Obeso et al., 1997). The present study indicates that STN high-frequency stimulation preserves the inhibitory influence of the striatonigral pathway and, depending on the intensity, this STN stimulation 
decreases or abolishes the excitatory influence of transsubthalamic pathways on SNR cells. Thus, by decreasing the relative efficiency of the trans-subthalamic circuits, the STN highfrequency stimulation introduces a bias between the direct and indirect trans-striatal circuits. This bias, which is opposite to that induced by the alteration of dopamine transmission in Parkinson's disease, might play a major role in the ability of STN stimulation to restore motor functions of parkinsonian patients.

\section{References}

Albin RL, Young AB, Penney JB (1989) The functional anatomy of basal ganglia disorders. Trends Neurosci 12:366-375.

Alexander GE, Crutcher MD (1990) Functional architecture of basal ganglia circuits: neural substrates of parallel processing. Trends Neurosci 13:266-271.

Aziz TZ, Peggs D, Sambrook MA, Crossman AR (1991) Lesion of the subthalamic nucleus for the alleviation of 1-methyl-4-phenyl-1, 2, 3, 6-tetrahydropyridine (MPTP)-induced parkinsonism in the primate. Mov Disord 6:288-292.

Benabid AL, Koudsie A, Benazzouz A, Fraix V, Ashraf A, Le Bas JF, Chabardes S, Pollak P (2000) Subthalamic stimulation for Parkinson's disease. Arch Med Res 31:282-289.

Benazzouz A, Gross C, Feger J, Boraud T, Bioulac B (1993) Reversal of rigidity and improvement in motor performance by subthalamic highfrequency stimulation in MPTP-treated monkeys. Eur J Neurosci 5:382-389.

Benazzouz A, Piallat B, Pollak P, Benabid AL (1995) Responses of substantia nigra pars reticulata and globus pallidus complex to high-frequency stimulation of the subthalamic nucleus in rats: electrophysiological data. Neurosci Lett 189:77-80.

Benazzouz A, Gao DM, Ni ZG, Piallat B, Bouali-Benazzouz R, Benabid AL (2000) Effect of high-frequency stimulation of the subthalamic nucleus on the neuronal activities of the substantia nigra pars reticulata and ventrolateral nucleus of the thalamus in the rat. Neuroscience 99:289-295.

Berendse HW, Groenewegen HJ (1991) The connections of the medial part of the subthalamic nucleus in the rat: evidence for a parallel organization. In: The basal ganglia III (Bernardi G, Carpenter MB, Di Chiara G, Morelli M, Stanzione P, eds), pp 89-98. New York: Plenum.

Bergman H, Wichmann T, DeLong MR (1990) Reversal of experimental parkinsonism by lesions of the subthalamic nucleus. Science 249:1436-1438.

Beurrier C, Bioulac B, Audin J, Hammond C (2001) High-frequency stimulation produces a transient blockade of voltage-gated currents in subthalamic neurons. J Neurophysiol 85:1351-1356.

Bevan MD, Magill PJ, Terman D, Bolam JP, Wilson CJ (2002) Move to the rhythm: oscillations in the subthalamic nucleus-external globus pallidus network. Trends Neurosci 25:525-531.

Bunney BS, Walters JR, Roth RH, Aghajanian GK (1973) Dopaminergic neurons: effect of antipsychotic drugs and amphetamine on single cell activity. J Pharmacol Exp Ther 185:560-571.

Burbaud P, Gross C, Bioulac B (1994) Effect of subthalamic high-frequency stimulation on substantia nigra pars reticulata and globus pallidus neurons in normal rats. J Physiol (Paris) 88:359-361.

Chesselet MF, Delfs JM (1996) Basal ganglia and movement disorders: an update. Trends Neurosci 19:417-422.

Chevalier G, Deniau JM (1990) Disinhibition as a basic process in the expression of striatal functions. Trends Neurosci 13:277-280.

Crossman AR, Walker RJ, Woodruff GN (1974) Problems associated with iontophoretic studies in the caudate nucleus and substantia nigra. Neuropharmacology 13:547-552.

DeLong MR (1990) Primate models of movement disorders of basal ganglia origin. Trends Neurosci 13:281-285.

Deniau JM, Hammond C, Riszk A, Feger J (1978a) Electrophysiological properties of identified output neurons of the rat substantia nigra (pars compacta and pars reticulata): evidences for the existence of branched neurons. Exp Brain Res 32:409-422.

Deniau JM, Hammond C, Chevalier G, Feger J (1978b) Evidence for branched subthalamic nucleus projections to substantia nigra, entopeduncular nucleus and globus pallidus. Neurosci Lett 9:117-121.

Deniau JM, Kitai ST, Donoghue JP, Grofova I (1982) Neuronal interactions in the substantia nigra pars reticulata through axon collaterals of the projection neurons. An electrophysiological and morphological study. Exp Brain Res 47:105-113.

Deniau JM, Menetrey A, Charpier S (1996) The lamellar organization of the rat substantia nigra pars reticulata: segregated patterns of striatal afferents and relationship to the topography of corticostriatal projections. Neuroscience 73:761-781.

Dostrovsky JO, Lozano AM (2002) Mechanisms of deep brain stimulation. Mov Disord 17 [Suppl 3]:S63-68.

Fujimoto K, Kita H (1992) Responses of rat substantia nigra pars reticulata units to cortical stimulation. Neurosci Lett 142:105-109.

Grofova I, Deniau JM, Kitai ST (1982) Morphology of the substantia nigra pars reticulata projection neurons intracellularly labeled with HRP. J Comp Neurol 208:352-368.

Guyenet PG, Aghajanian GK (1978) Antidromic identification of dopaminergic and other output neurons of the rat substantia nigra. Brain Res 150:69-84.

Hammond C, Deniau JM, Rizk A, Feger J (1978) Electrophysiological demonstration of an excitatory subthalamonigral pathway in the rat. Brain Res 151:235-244.

Hashimoto T, Elder CM, Okun MS, Patrick SK, Vitek JL (2003) Stimulation of the subthalamic nucleus changes the firing pattern of pallidal neurons. J Neurosci 23:1916-1923.

Joel D, Weiner I (1997) The connections of the primate subthalamic nucleus: indirect pathways and the open-interconnected scheme of basal ganglia-thalamocortical circuitry. Brain Res Rev 23:62-78.

Kita H (1994) Physiology of two disynaptic pathways from the sensorimotor cortex to the basal ganglia output nuclei. In: The basal ganglia IV (Percheron G, McKenzie JS, Feger J, eds), pp 263-276. New York: Plenum.

Kita H, Kitai ST (1994) The morphology of globus pallidus projection neurons in the rat: an intracellular staining study. Brain Res 636:308-319.

Kitai ST, Deniau JM (1981) Cortical inputs to the subthalamus: intracellular analysis. Brain Res 214:411-415.

Kolomiets BP, Deniau JM, Glowinski J, Thierry AM (2003) Basal ganglia and processing of cortical information: functional interactions between trans-striatal and trans-subthalamic circuits in the substantia nigra pars reticulata. Neuroscience 117:931-938.

Levy R, Lang AE, Dostrovsky JO, Pahapill P, Romas J, Saint-Cyr J, Hutchison WD, Lozano AM (2001) Lidocaine and muscimol microinjections in subthalamic nucleus reverse Parkinsonian symptoms. Brain 124:2105-2118.

Levy R, Ashby P, Hutchison WD, Lang AE, Lozano AM, Dostrovsky JO (2002) Dependence of subthalamic nucleus oscillations on movement and dopamine in Parkinson's disease. Brain 125:1196-1209.

Limousin P, Pollak P, Benazzouz A, Hoffmann D, Broussolle E, Perret JE, Benabid AL (1995) Bilateral subthalamic nucleus stimulation for severe Parkinson's disease. Mov Disord 10:672-674.

Magarinos-Ascone C, Pazo JH, Macadar O, Buno W (2002) Highfrequency stimulation of the subthalamic nucleus silences subthalamic neurons: a possible cellular mechanism in Parkinson's disease. Neuroscience 115:1109-1117.

Mailly P, Charpier S, Menetrey A, Deniau JM (2003) Three-dimensional organization of the recurrent axon collateral network of the substantia nigra pars reticulata neurons in the rat. J Neurosci 23:5247-5257.

Maurice N, Deniau JM, Glowinski J, Thierry AM (1998) Relationships between the prefrontal cortex and the basal ganglia in the rat: physiology of the corticosubthalamic circuits. J Neurosci 18:9539-9546.

Maurice N, Deniau JM, Glowinski J, Thierry AM (1999) Relationships between the prefrontal cortex and the basal ganglia in the rat: physiology of the cortico-nigral circuits. J Neurosci 19:4674-4681.

Mink JW, Thach WT (1993) Basal ganglia intrinsic circuits and their role in behavior. Curr Opin Neurobiol 3:950-957.

Monakow KH, Akert K, Kunzle H (1978) Projections of the precentral motor cortex and other cortical areas of the frontal lobe to the subthalamic nucleus in the monkey. Exp Brain Res 33:395-403.

Nambu A, Takada M, Inase M, Tokuno H (1996) Dual somatotopical representations in the primate subthalamic nucleus: evidence for ordered but reversed body-map transformations from the primary motor cortex and the supplementary motor area. J Neurosci 16:2671-2683.

Nambu A, Tokuno H, Hamada I, Kita H, Imanishi M, Akazawa T, Ikeuchi Y, 
Hasegawa N (2000) Excitatory cortical inputs to pallidal neurons via the subthalamic nucleus in the monkey. J Neurophysiol 84:289-300.

Obeso JA, Rodriguez MC, DeLong MR (1997) Basal ganglia pathophysiology. A critical review. Adv Neurol 74:3-18.

Paxinos G, Watson C (1986) The rat brain in stereotaxic coordinates, Ed 2. London: Academic.

Ranck Jr JB (1975) Which elements are excited in electrical stimulation of mammalian central nervous system: a review. Brain Res 98:417-440.

Ryan LJ, Clark KB (1992) Alteration of neuronal responses in the subthalamic nucleus following globus pallidus and neostriatal lesions in rats. Brain Res Bull 29:319-327.

Ryan LJ, Sanders DJ (1994) Subthalamic nucleus and globus pallidus lesions alter activity in nigrothalamic neurons in rats. Brain Res Bull 34:19-26.

Salin P, Manrique C, Forni C, Kerkerian-Le Goff L (2002) High-frequency stimulation of the subthalamic nucleus selectively reverses dopamine denervation-induced cellular defects in the output structures of the basal ganglia in the rat. J Neurosci 22:5137-5148.

Smith Y, Bevan MD, Shink E, Bolam JP (1998) Microcircuitry of the direct and indirect pathways of the basal ganglia. Neuroscience 86:353-387.

Vitek JL (2002) Mechanisms of deep brain stimulation: excitation or inhibition. Mov Disord 17 [Suppl 3]:S69-72.

Windels F, Bruet N, Poupard A, Urbain N, Chouvet G, Feuerstein C, Savasta M (2000) Effects of high-frequency stimulation of subthalamic nucleus on extracellular glutamate and GABA in substantia nigra and globus pallidus in the normal rat. Eur J Neurosci 12:4141-4146.

Windels F, Bruet N, Poupard A, Feuerstein C, Bertrand A, Savasta M (2003) Influence of the frequency parameter on extracellular glutamate and gamma-aminobutyric acid in substantia nigra and globus pallidus during electrical stimulation of subthalamic nucleus in rats. J Neurosci Res 72: 259-267. 